\title{
PEMAKAIAN TANAH DIATOMAE SEBAGAI SUBSTITUSI SEMEN FAS 0.30 DENGAN PERLAKUAN KALSINASI UNTUK PRODUKSI BETON NORMAL
}

\author{
Emi Maulani \\ Jurusan Teknik Sipil Universitas Malikussaleh \\ email: emi.maulani@gmail.com
}

\begin{abstract}
Abstrak
Tanah diatomae memiliki sifat pozzolan yang mirip dengan bahan pozzolan lainnya seperti fly ash dan metakaolin. Tujuan penelitian ini adalah untuk membuat beton mutu normal dengan penambahan tanah diatomae dari Desa Lampanah, Kabupaten Aceh Besar sebagai substitusi sebagian semen dan membandingkan dengan karakteristik beton berbahan dasar semen sehingga dapat mengurangi biaya produksi beton dan dapat meminimalisir beban polutan lingkungan tanpa mempengaruhi kualitas secara teknis. Benda uji yang dibuat berupa silinder dengan ukuran diameter $100 \mathrm{~mm}$ dan tinggi 200 mm dengan faktor air semen FAS 0.30 dengan persentase kadar substitusi tanah diatomae $0 \%, 10 \%, 20 \%, 30 \%$ dan $40 \%$ menggantikan semen dengan variasi tanah diatomae kalsinasi dan tanpa kalsinasi. Pengujian dilakukan pada umur 7 hari, 28 hari dan 56 hari. Dari hasil penelitian sifat kimia tanah diatomae memiliki kandungan $\mathrm{SiO}_{2} 62.28 \%, \mathrm{CaO} 8.28 \%, \mathrm{Fe}_{2} \mathrm{O}_{3} 1.79 \%$, dan $\mathrm{Al}_{2} \mathrm{O}_{3} 9.52 \%$. Nilai kuat tekan beton mengalami penurunan sebanding dengan penambahan kadar tanah diatomae terhadap semen. Namun substitusi semen dengan tanah diatomae sampai $30 \%$ nilai kuat tekan yang diperoleh masih termasuk kategori beton struktural menurut peraturan SNI 03-6468-2000. Nilai rata-rata kuat tekan beton dengan FAS 0.30 tanpa kalsinasi pada umur 56 hari adalah $38.93 \mathrm{MPa}$ ( tanah diatomae 0\%); $35.60 \mathrm{MPa}$ (tanah diatomae $10 \%$ ); $28.31 \mathrm{MPa}$ (tanah diatomae 20\%); $23.73 \mathrm{MPa}$ (tanah diatomae 30\%); 17.28 MPa (tanah diatomae 40\%).
\end{abstract}

Kata kunci: substitusi semen, tanah diatomae, beton mutu normal, kalsinasi

\section{Pendahuluan}

Penggunaan beton sebagai material konstruksi dalam pembangunan berbagai infrastruktur terjadi peningkatan yang signifikan dari tahun ke tahun. Secara nasional, penggunaan beton di dunia konstruksi di Indonesia hampir mencapai $60 \%$. Untuk membuat beton mutu normal (normal-strength concretes) yang kekuatan tekannya mulai $20 \mathrm{MPa}$ sampai $50 \mathrm{MPa}$ dibutuhkan jumlah semen yang relatif banyak, yaitu berkisar $400 \mathrm{~kg} / \mathrm{m}^{3}$ sampai $600 \mathrm{~kg} / \mathrm{m}^{3}$, selain itu, proses produksi semen pada industri fabrikasi juga tidak ramah lingkungan. Untuk menghasilkan semen Portland dibutuhkan kandungan bahan baku berbasis Calcium berupa tanah liat dan batu kapur yang tinggi dengan temperatur produksi untuk menghaluskan klinker tersebut mencapai lebih $1500^{\circ} \mathrm{C}$ serta konsumsi bahan bakar yang tinggi, yang kesemuanya dapat meningkatkan emisi karbon $\left(\mathrm{CO}_{2}\right)$ ke lapisan atmosfer bumi yang dapat mengakibatkan efek rumah kaca sebagai pemicu fenomena pemanasan global dan perubahan iklim. Oleh karena itu perlu dilakukan terobosan baru dalam mencari material alternatif untuk mengganti penggunaan semen sebagai bahan ikat utama, memiliki sifat mekanis yang baik dan dapat berfungsi sebagai material pengikat yang bersifat cementitious seperti

Pemakaian tanah diatomae sebagai substitusi semen fas 0.30 dengan perlakuan 
semen. Berdasarkan Dinas Pertambangan dan Energi Provinsi Aceh tahun 2012, di Kabupaten Aceh Besar sebaran tanah diatomae banyak terdapat di Desa Lampanah dengan estimasi 40.353.700.00 ton.

Deposit tanah diatomae atau diatomite di Kabupaten Aceh Besar cukup tinggi dengan estimasi 40.353.700.00 ton (Dinas Pertambangan dan Energi Provinsi Aceh, 2012). Tanah diatomae memiliki keunggulan berdaya serap tinggi, dapat diperbaharui, mudah diperoleh dengan harga yang tidak mahal dan bahan dasar yang merupakan sumber daya alam yang dapat dimanfaatkan untuk kesejahteraan masyarakat. Tanah diatomae termasuk salah satu bahan pozzolan.

Menurut Bastis (2004) keuntungan beton yang mengandung pozzolan adalah mempunyai permeabilitas rendah dan ketahanan tinggi dalam waktu lama terhadap serangan sulfat. Kelemahan pozzolan adalah dalam kadar yang banyak akan mengurangi kekuatan beton umur 28 hari dan membutuhkan waktu perawatan yang lama akibat reaksi pozzolanik yang lambat.

Untuk membuat beton mutu normal (normal-strength concretes) yang kekuatan tekannya mulai $20 \mathrm{MPa}$ sampai $50 \mathrm{MPa}$ dibutuhkan jumlah semen yang cukup banyak, yaitu berkisar $400 \mathrm{~kg} / \mathrm{m}^{3}$ sampai $600 \mathrm{~kg} / \mathrm{m}^{3}$. Dengan harga semen yang relatif mahal menjadikan biaya produksi beton menjadi tidak murah. Selain itu, proses produksi semen pada pabrik industri juga tidak ramah lingkungan. Untuk menghasilkan Semen Portland dibutuhkan kandungan bahan baku berbasis Calcium berupa tanah liat dan batu kapur yang tinggi dengan temperatur produksi untuk menghaluskan klinker tersebut mencapai lebih $1500^{\circ} \mathrm{C}$, serta konsumsi bahan bakar yang tinggi, yang kesemuanya dapat meningkatkan emisi karbon $\left(\mathrm{CO}_{2}\right)$ ke lapisan atmosfer bumi. Produksi 1 ton semen Portland melepaskan 1 ton $\mathrm{CO}_{2}$ ke atmosfer, yang dapat mengakibatkan efek rumah kaca sebagai pemicu fenomena pemanasan global dan perubahan iklim. Oleh karena itu perlu dilakukan terobosan baru dalam mencari material alternatif lain seperti tanah diatomae yang tersedia di alam dan memiliki sifat pozzolan yang bersifat cementitious untuk mengganti penggunaan sebagian semen sebagai bahan ikat utama untuk komposisi yang sama, sehingga dapat mengurangi pemakaian sumber daya alam dan sumber energi dan mengurangi beban polutan lingkungan. Dengan mengurangi konsumsi energi dan emisi $\mathrm{CO}_{2}$ bila digunakan sebagai pengganti sebagian semen maka biaya produksi beton dapat dikurangi tanpa mempengaruhi kualitasnya (Kurtis, 2002). Dalam paper ini disajikan hasil studi penggunaan tanah diatomae sebagai pengganti sebagian semen dalam memproduksi beton mutu normal.

\section{Tinjauan Kepustakaan}

\subsection{Bahan Tambahan Semen (Supplementary cementitious materials)}

Meyer (2002) menyatakan bahwa industri semen adalah produsen gas rumah kaca dan pengguna energi yang terbesar di dunia. John (2003) bahkan menyatakan bahwa akibat yang harus diderita oleh masyarakat global akibat kehadiran industri semen adalah pemanasan global. Bahkan menurut Humphreys dan Mahasenan (2002), diperkirakan bahwa industri semen bertanggung jawab terhadap 3\% dari emisi gas rumah kaca dunia dan 5\% dari emisi gas $\mathrm{CO}_{2}$ dunia.

Upaya pengurangan pemakaian semen dapat dicapai dengan penggunaan material cementitious tambahan (supplementary cementitious materials, SCM) antara lain abu terbang (fly ash), silica-fume, pozzolan alam, slag, dan lain-lain 
(NRMCA, 2000; Naik, 2005). Rocktron (2007) secara sederhana membagi jenis pozzolan menurut asalnya menjadi dua kategori yaitu pozzolan alam, diantaranya vulkanis (volcanic ash), pumice, tufa (tuff), tanah diatomae (diatomaceous earth), dan opaline shale; dan pozzolan buatan seperti fly ash dan produk abu terbang yang berasal dari pembakaran batu bara pada pembangkit listrik, abu sekam padi (rice husk ash), debu bata (brick dust), kaolin berkapur (calcined kaolin), condensed silica fume, ground granulated blast furnace slag (GGBS) dan beberapa slag metalurgis.

\subsection{Tanah Diatomae (diatomite)}

Tanah diatomae termasuk tipe SCM atau bahan tambahan pengganti sebagian semen alami berdasarkan ASTM C 618 Class N. Tanah diatomae memiliki sifat pozzolan yang mirip dengan bahan pozzolan lainnya seperti fly ash dan metakaolin (Sanchez de Rojas, 1999).

\subsubsection{Sifat dan Karakteristik Tanah Diatomae}

Diatomae memiliki sifat dasar yakni strukturnya unik, berat jenisnya rendah $( \pm 0,45)$, permukaannya luas dan berpori-pori, warnanya putih-coklat (tergantung kontaminasinya), kemampuan daya hantar listrik atau panas rendah serta tidak abrasif (Rahmah, dkk, 2011).

Fragoulisa, et. al. (2004), menemukan lightweight aggregates (LWA) hasil penelitian laboratorium dengan menggunakan bahan dasar diatomae memiliki kekuatan dan kepadatan mirip dengan LWA komersial yang berasal dari Jerman dan Denmark. Berdasarkan analisis kimia, fisik dan mineralogi dan tes pada material-material mentah dan produk disinter LWA yang diproduksi oleh batuan liat diatomae Yunani dapat dimanfaatkan untuk produksi LWA pada skala industri. Namun, produksi LWA pada skala industri dan untuk aplikasi yang berbeda dan beragam memerlukan penelitian lebih lanjut.

\subsubsection{Mikrostruktural dan Mineralogi Tanah Diatomae}

Menurut Khan (1980) secara kimiawi, komposisi utama tanah diatomae berupa silika amorf yang kadarnya mencapai sekitar 55-70\%, tergantung lingkungan setempat. Kadar senyawa silika dalam tanah diatomae sangat bervariasi, demikian juga strukturnya. Hal ini sangat dipengaruhi oleh asalnya. Hasil pengujian scanning electron microscopy (SEM), struktur tanah diatomae dari Ellasona, Yunani dapat diperlihatkan pada Gambar 1.

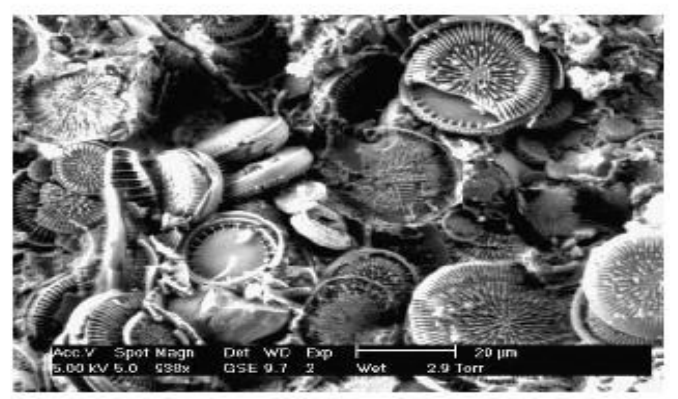

Gambar 1 Struktur tanah diatomae berbentuk cakram dari Elassona, Yunani Sumber: Fragoulis (2005)

Pemakaian tanah diatomae sebagai substitusi semen fas 0.30 dengan perlakuan kalsinasi Untuk produksi beton normal - Emi Maulani 
Kastis, et. al. (2006) melakukan penelitian dengan mengganti sebagian semen dengan diatomae $0 \%, 10 \%, 20 \%$ dan 35\%. Hasilnya menunjukkan bahwa campuran semen yang memiliki kandungan $10 \%$ diatomae, memiliki kekuatan tekan yang sama dan sesuai dengan semen Portland. Hasil penelitian Pimraksa dan Chindaprasirt (2009) menunjukkan bahwa tanah diatomae memiliki sifat pozzolan dan dapat digunakan untuk membuat batu bata ringan. Batu bata yang dibuat dengan diatomae dan $15 \%$ kapur serta $5 \%$ gypsum menunjukkan kekuatan yang cukup tinggi, yaitu $14,5 \mathrm{MPa}$ dan berat jenis yang rendah, yaitu $0,88 \mathrm{~g} / \mathrm{cm}^{3}$.

\subsection{Kuat Tekan dan Modulus Elastisistas Beton}

Mulyono (2006) mengemukakan faktor yang dapat mempengaruhi kuat tekan beton adalah proporsi bahan penyusun, metode pencampuran, perawatan, dan keadaan pada saat pengecoran. Menurut Wang dan Salmon (1990), modulus elastisitas $(E)$ dihitung pada saat tegangan mencapai $25 \%$ sampai $50 \%$ dari kuat tekan $\left(f^{\prime}{ }^{\prime}\right)$ beton.

\section{Metode Penelitian}

Pada penelitian ini direncanakan campuran beton dengan faktor air semen (FAS) 0.30. Untuk masing-masing campuran, berat semen yang digunakan digantikan dengan tanah diatomae yang sudah dikalsinasi dan tanpa kalsinasi sebanyak $0 \%, 10 \%, 20 \%, 30 \%$ dan $40 \%$. Tanah diatomae yang dipakai mempunyai spesific gravity sebesar 1.5 dan komposisi kimia sebagai berikut: $62,28 \% \mathrm{SiO}_{2}, \mathrm{CaO} 8,28 \%, \mathrm{Fe}_{2} \mathrm{O}_{3} 1,79 \%$ dan $\mathrm{Al}_{2} \mathrm{O}_{3}$ 9,52\%. Sebagai agregat digunakan pasir halus, pasir kasar dan kerikil yang berasal dari Sungai Krueng Aceh dan mempunyai sifat fisis seperti pada Tabel 1 .

Tabel 1 Sifat fisis agregat

\begin{tabular}{|l|c|c|c|c|}
\hline \multirow{2}{*}{ Agregat } & \multirow{2}{*}{ Berat Volume } & \multicolumn{2}{|c|}{ Specific Gravity } & \multirow{2}{*}{$\begin{array}{c}\text { Fineness } \\
\text { Modulus }\end{array}$} \\
\cline { 3 - 4 } & & OD & SSD & Mon \\
\hline Pasir halus & 1,62 & 2,57 & 2,63 & 2,31 \\
\hline Pasir kasar & 1,79 & 2,57 & 2,64 & 4,65 \\
\hline Kerikil & 1,82 & 2,77 & 2,81 & 6,68 \\
\hline
\end{tabular}

Sebagai semen digunakan semen Portland produksi Semen Andalas. Air untuk pencampuran beton yang digunakan adalah air dari PDAM Tirta Daroy. Benda uji yang digunakan silinder berdiameter $100 \mathrm{~mm}$ dan tinggi $200 \mathrm{~mm}$. Pengujian tekan dilakukan pada saat benda uji berumur 7 hari, 28 hari dan 56 hari. Jumlah benda uji untuk masing-masing perlakuan adalah sebanyak 3 buah, sehingga jumlah benda uji keseluruhan adalah sebanyak 90 buah. Rencana campuran beton untuk $1 \mathrm{~m} 3$ volume beton diperlihatkan pada Tabel 2 .

Tabel 2 Rencana campuran beton dengan diatomae sebagai substitusi semen

\begin{tabular}{|c|c|c|c|c|c|c|c|}
\hline \multirow[b]{2}{*}{$\sum_{1}^{\infty}$} & \multirow[b]{2}{*}{$\begin{array}{c}\% \\
\text { Diatomae }\end{array}$} & \multicolumn{6}{|c|}{ Material (Berat, kg) } \\
\hline & & Air & Semen & Kerikil & Pasir Kasar & Pasir halus & $\begin{array}{c}\text { Tanah } \\
\text { diatomae }\end{array}$ \\
\hline \multirow{5}{*}{ ల్ల } & $0 \%$ & 192.62 & 642.05 & 927.77 & 231.94 & 386.57 & 0 \\
\hline & $10 \%$ & 192.62 & 577.85 & 927.77 & 231.94 & 386.57 & 64.21 \\
\hline & $20 \%$ & 192.62 & 513.64 & 927.77 & 231.94 & 386.57 & 128.41 \\
\hline & $30 \%$ & 192.62 & 449.44 & 927.77 & 231.94 & 386.57 & 192.62 \\
\hline & $40 \%$ & 192.62 & 385.23 & 927.77 & 231.94 & 386.57 & 256.82 \\
\hline
\end{tabular}

Pemakaian tanah diatomae sebagai substitusi semen fas 0.30 dengan perlakuan kalsinasi Untuk produksi beton normal - Emi Maulani 


\begin{tabular}{|c|c|c|c|c|c|c|c|}
\hline & $0 \%$ & 192.62 & 642.05 & 927.77 & 231.94 & 386.57 & 0 \\
\cline { 2 - 8 } & $10 \%$ & 192.62 & 577.85 & 927.77 & 231.94 & 386.57 & 64.21 \\
\hline \multirow{2}{*}{\begin{tabular}{c}
$*$ \\
\cline { 2 - 7 }
\end{tabular}} & $20 \%$ & 192.62 & 513.64 & 927.77 & 231.94 & 386.57 & 128.41 \\
\cline { 2 - 8 } & $30 \%$ & 192.62 & 449.44 & 927.77 & 231.94 & 386.57 & 192.62 \\
\cline { 2 - 8 } & $40 \%$ & 192.62 & 385.23 & 927.77 & 231.94 & 386.57 & 256.82 \\
\hline
\end{tabular}

\section{Hasil dan Pembahasan}

\subsection{Kuat Tekan Beton}

Kuat tekan beton merupakan indikator utama dalam penelitian ini yang diuji pada umur 7 hari, 28 hari dan 56 hari dan besarnya kuat tekan beton rata-rata dapat dilihat pada Tabel 3.

Tabel 3 Kuat tekan beton rata-rata dengan diatomae sebagai subsitusi semen

\begin{tabular}{|c|c|c|c|c|c|}
\hline \multirow{2}{*}{ FAS } & \multirow{2}{*}{$\begin{array}{c}\% \\
\text { Diatomae }\end{array}$} & \multicolumn{3}{|c|}{ Kuat Tekan Rata-rata (MPa) } & \multirow{2}{*}{ Mutu Beton } \\
\hline & & 7 Hari & 28 Hari & 56 Hari & \\
\hline \multirow{5}{*}{ 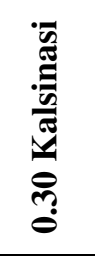 } & 0 & 31.23 & 33.10 & 38.93 & \multirow{4}{*}{ Structural Concrete } \\
\hline & 10 & 26.23 & 27.48 & 29.98 & \\
\hline & 20 & 20.19 & 21.86 & 24.98 & \\
\hline & 30 & 15.20 & 18.74 & 21.65 & \\
\hline & 40 & 9.16 & 13.74 & 18.32 & $\begin{array}{c}\text { Non Structural } \\
\text { Concrete }\end{array}$ \\
\hline \multirow{5}{*}{ 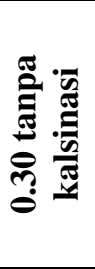 } & 0 & 31.23 & 33.10 & 38.93 & \multirow{4}{*}{ Structural Concrete } \\
\hline & 10 & 24.98 & 29.14 & 35.60 & \\
\hline & 20 & 18.74 & 21.02 & 28.31 & \\
\hline & 30 & 13.53 & 17.07 & 23.73 & \\
\hline & 40 & 7.08 & 11.45 & 17.28 & $\begin{array}{c}\text { Non Structural } \\
\text { Concrete }\end{array}$ \\
\hline
\end{tabular}

Hubungan kuat tekan beton dan persentase tanah diatomae sebagai substitusi semen untuk FAS 0.30 tanpa kalsinasi dan kalsinasi diperlihatkan pada Gambar 2 dan 3.

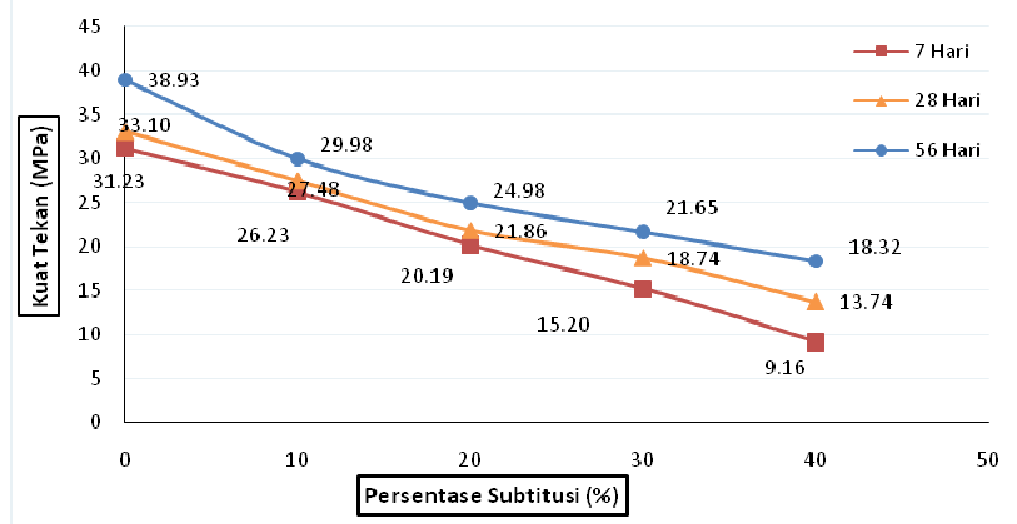

Gambar 2 Hubungan kuat tekan beton dengan persentase tanah diatomae sebagai substitusi semen dengan FAS 0.30 kalsinasi 


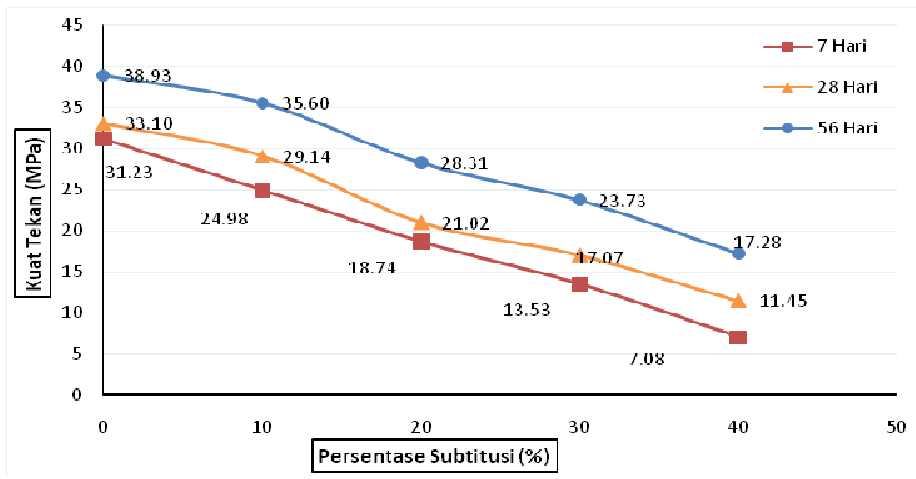

Gambar 3 Hubungan kuat tekan beton dengan persentase tanah diatomae sebagai substitusi semen dengan FAS 0.30 tanpa kalsinasi

Dari Gambar 2 dan 3 di atas terlihat bahwa kuat tekan beton menurun sebanding dengan meningkatnya jumlah semen yang digantikan oleh tanah diatomae. Namun demikian, sampai substitusi semen sebanyak $30 \%$ beton yang dihasilkan masih termasuk kategori beton struktural mutu sedang, karena kuat tekan yang dihasilkan berada pada selang 21-40 MPa (SNI 03-6468-2000).

\subsection{Hubungan modulus elastisitas dan kuat tekan beton}

Hubungan modulus elastisitas dan kuat tekan beton dengan diatomae sebagai substitusi semen diperlihatkan pada Gambar 4.

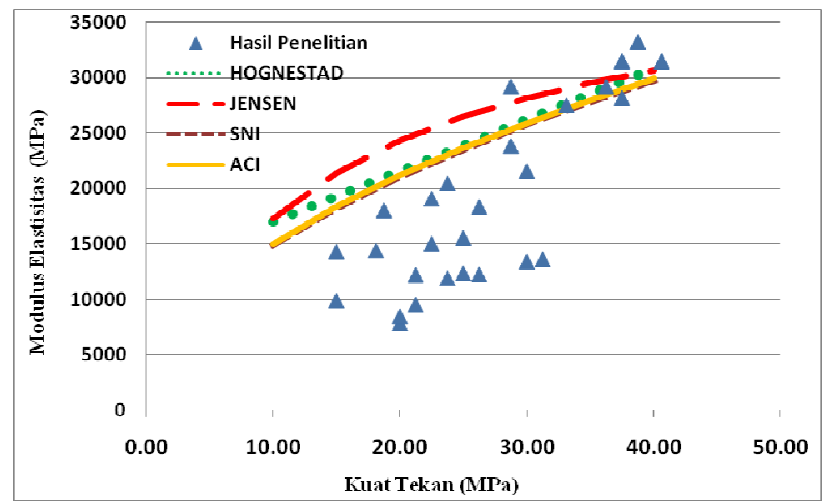

Gambar 4 Hubungan modulus elastisitas dan kuat tekan beton dengan pemakaian tanah diatomae sebagai substitusi semen.

Dari Gambar 4 terlihat bahwa modulus elastisitas meningkat seiring dengan meningkat kuat tekan beton. Pada gambar tersebut juga di plot hubungan modulus elastisitas dan kuat tekan beton berdasarkan rumus empiris yang diusulkan Hognestad, Jensen, ACI (dikutip dari T. Y. Lin, 1996) dan SNI 03-2847-2002.

Untuk kuat tekan diatas $20 \mathrm{MPa}$ modulus elastisitas yang diperoleh sesuai dengan yang diajukan oleh Hognestad, Jensen, ACI dan SNI 03-2847-2002. Untuk kuat tekan dibawah $20 \mathrm{MPa}$ umumnya modulus elastisitas yang diperoleh lebih rendah dari yang diajukan oleh Hognestad, Jensen, ACI dan SNI 03-28472002 . 


\subsection{Persamaan untuk memprediksi kuat tekan beton dengan menggunakan tanah diatomae.}

Untuk memprediksi kuat tekan beton dengan diatomae sebagai substitusi semen maka diusulkan persamaan untuk menghitung kuat tekan beton tersebut. Data semua kuat tekan pada berbagai persentase diatomae yang digunakan dinormalisasi dengan kuat tekan beton tanpa penggunaan diatomae (diatomae 0\%). Dengan menggunakan analisis regresi linear sederhana dapat ditentukan sebuah persamaan untuk menghitung kuat tekan beton dengan diatomae sebagai substitusi semen sebagai berikut:

$$
f_{c}^{\prime}=f_{c o}{ }^{\prime}(1,0-0,013 d)
$$

di mana $f_{c}$ ' adalah kuat tekan beton dengan diatomae sebagai substitusi semen, $f_{c o}$ ' adalah kuat tekan beton tanpa diatomae, $d$ adalah persentase diatomae. Data hasil pengujian di laboratorium bersama dengan persamaan yang diusulkan di atas di plot pada Gambar 5 di bawah.

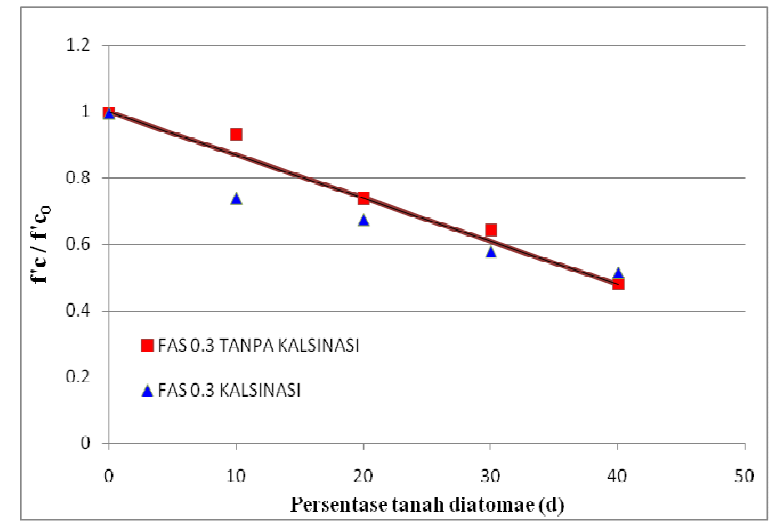

Gambar 5 Persamaan untuk memprediksi kuat tekan beton dengan diatomae sebagai substitusi semen beserta data hasil pengujian

\section{Kesimpulan dan Saran}

\subsection{Kesimpulan}

Dari hasil penelitian dan pembahasan dapat diambil beberapa kesimpulan sebagai berikut :

1. Tanah diatomae dari Desa Lampanah bisa digunakan sebagai salah satu material alternatif natural SCM.

2. Beton struktural dapat dihasilkan sampai penggantian semen dengan tanah diatomae sebanyak $30 \%$.

3. Perlakuan kalsinasi hanya berpengaruh pada umur 28 hari.

4. Modulus elastisitas meningkat seiring dengan meningkat kuat tekan beton. Modulus elastisitas yang diperoleh berada pada garis persamaan yang diajukan oleh Hognestad, Jensen, ACI dan SNI.

5. Sebuah persamaan linier hubungan kuat tekan beton dengan tanah diatomae sebagai subsitusi semen dengan persentase tanah diatomae telah diajukan sebagai hasil dari penelitian. 


\subsection{Saran}

Penelitian ini diharapkan dapat dilanjutkan oleh para peneliti lainnya, terutama terhadap beberapa permasalahan berikut :

1. Penelitian lanjutan terhadap tanah diatomae dapat dilakukan dengan perhitungan mix design berdasarkan perbandingan volume karena berat jenis tanah diatomae sangat rendah.

2. Untuk hasil yang lebih tinggi kuat tekannya perlu dilakukan penelitian lanjutan dengan perlakuan kalsinasi suhu yang mencapai diatas $600^{\circ} \mathrm{C}$

3. Untuk pengujian umur beton perlu dilakukan penelitian lebih lanjut terhadap sifat mekanis beton untuk umur 90 hari.

\section{Daftar Kepustakaan}

ASTM., 1995. Concrete and Agregat, Philadelphia: Annual Book of ASTM Standard Vo.04.02.1995.

Fragoulis, D, Stamatakis, M. G, Papageorgio, dan Chaniotakis, E., 2005. The physical and mechanical properties of composite cements manufactured with calcareous and clayey Greek diatomite mixtures. Journal Cement \& Concrete Composites 27 (2005) 205-209.

Humphreys, K., dan Mahasenan, M., 2002. "Climate Change”, Towards a Sustainable Cement Industry, Battelle-World Council for Sustainable Development.

Kastis, D, Kakali, G, Tsivilis, S, dan Stamatakis, M. G., 2006. Properties and hydration of blended cements with calcareous diatomite. Cement and Concrete Research 36 (2006) 1821-1826

Kurtis, K., 2002. Supplementary Cementing Materials. Georgia Tech, PCA CD038, School of Civil and Environmental Engineering Georgia Institute of Technology Atlanta, Georgia.

Meyer, C. 2002, Concrete and Sustainable Development, Special Publication ACI 206, Concrete Materials to Application - A Tribute to Surendra P. Shah, American Concrete Institute, Farmington Hills, MI

NRMCA., 2000, Concrete in Practise: what, Why, and How, CIP30Supplementary Cementitious Materials, Silver Spring, MD.

Naik, TR. 2005. Sustainability of Concrete and Cement Industries, CBU-200415;REP-562, January, Center for By-Products Utilizatons, Department of Civil Engineering and Mechanics, College of Engineering and Applied Science, The University of Wisconsin, Milwaukee, USA.

RockTron., 2007."A Brief History of Pozzolans, PFA, and Cement", www.rocktronplc.com/PDFs/A\%20Brief\%20History\%20of\%20Pozzolans, \%20PFA \%20\&\%20Cement.pdf.

Sanchez de Rojas, M. I, J. Rivera, dan M. Frias., 1999. Influence of the microsilica state on pozzolanic reaction rate. Cem. Concr. Res. 29 (1999) 945-949. 